\title{
Los mejores años de la educación en América Latina, 1950-1980
}

\author{
The best years of education in Latin America, 1950-1980
}

\author{
Andrés Donoso-Romo ${ }^{1}$ \\ Universidad de Playa Ancha \\ Investigador del Centro de Estudios Avanzados \\ Valparaíso, Chile \\ andres.donoso@upla.cl
}

Recibido: 20 agosto 2013 Aceptado: 26 junio 2014 Corregido: 30 junio 2014

\begin{abstract}
Resumen: En este artículo se estudiarán los mejores años de la educación en América Latina (1950-1980), aquellos en que por primera vez gran parte de la población regional compartió una percepción favorable sobre la educación. En la primera parte se observará uno de los fenómenos más característicos del escenario educacional latinoamericano del periodo, el aumento explosivo de la cobertura educacional. En la segunda se analizará otra tendencia de gran relevancia en estas décadas, la seguidilla de reformas que afectaron a los sistemas educacionales. En la tercera se detallarán las principales críticas que se levantaron en contra de los sistemas escolares. Y en la última parte, a modo de conclusión, se reseñarán los antecedentes que hicieron que a fines de los setenta, y comienzos de los ochenta, cambiaran las claves generales de la educación en Latinoamérica.
\end{abstract}

Palabras claves: Educación, historia latinoamericana, sistema escolar, educación no formal.

\begin{abstract}
This article will study the best years of education in Latin America (1950-1980); where a great majority of the regional population shared a positive perception of education of the first time. The first part will have a look at one of the most unique Latin American educational phenomena of the era-the exponential increase of educational coverage. The second part will analyze other important tendencies during these decades - the implementation of reforms that affected to educational systems. The third part will point out in detail the major critiques against educational systems. The last part, as a way of conclusion, will explain the antecedents that, in the late 70s and early 80s, will change the general basis of education in Latin America.
\end{abstract}

Keywords: Education, Latin-American history, educational system, non formal education.

$1 \quad$ Antropólogo social por la Universidad de Chile (2003). Maestro en Estudios Latinoamericanos por la Universidad de Chile (2007). Doctor en Integración de América Latina por la Universidad de San Pablo, Brasil (2013). Investigador del Centro de Estudios Avanzados de la Universidad de Playa Ancha, Valparaíso, Chile. Cuenta con dos libros publicados: Educación y nación al sur de la frontera, Editado en Santiago de Chile por Editorial Pehuén, año 2008, e Identidad y educación en América Latina, editado en Caracas por Editorial Laboratorio Educativo el año 2012. Los resultados de sus investigaciones, en forma de artículos, capítulos de libros y actas de congresos, han sido publicados en una treintena de medios académicos de Argentina, Chile, Colombia, Ecuador, México, Panamá, República Dominicana y Venezuela. Ha sido conferencista en universidades de España, México y Brasil. Entre sus artículos destacan: "Iván Illich, la desescolarización y la revolución cultural: una lectura desde/para América Latina", publicado en los Cuadernos Americanos de la Universidad Nacional Autónoma de México; "Repensando nuestro inédito viable: una invitación al diálogo", publicado en la Revista de Pedagogía Crítica Paulo Freire de la Universidad Academia de Humanismo Cristiano; y "La nación como protagonista de la educación en América Latina, 1870-1930", publicado en la Revista de Historia de la Educación Latinoamericana de la Universidad Pedagógica y Tecnológica de Colombia. 


\section{Introducción}

En el presente artículo se informan parte de los resultados de un estudio conducente al grado de doctor en ciencias con mención en integración de América Latina, otorgado por la Universidad de San Pablo (USP). Con una escritura que mixtura los géneros "reporte de investigación" y "ensayo" se estudiará un período reciente de la historia educacional latinoamericana, el tercer cuarto del siglo XX, es decir, los años que van desde 1950 hasta 1980. Acercamiento que, confiamos, será de utilidad a todos los interesados en obtener más profundidad histórica para las problemáticas y discusiones actuales en el campo educacional y, en especial, a los que requieran dimensionar más ajustadamente las reflexiones educacionales que tuvieron los latinoamericanos de entonces.

Para identificar los grandes procesos educacionales vividos en estas décadas se analizaron, en sus contenidos, las principales obras en la materia (escritas por intelectuales o instituciones de dichos años o de la actualidad). Gracias a estos análisis se estableció que entre las marcas más significativas de este período están el fuerte aumento de la matrícula escolar y la implementación de sucesivas reformas educacionales. Fenómenos que se describen en profundidad en los dos primeros apartados de este trabajo. Fruto de estos análisis es que también se pudieron identificar las principales problemáticas que surgieron aparejadas a los procesos descritos, las cuales se caracterizan en la tercera sección del artículo. En la última parte, en tanto, se anotan las causas que hicieron que a fines de la década de los setenta, y comienzos de los ochenta, los procesos descritos se interrumpieran y se origine un escenario educacional que tendrá en el neoliberalismo a uno de sus antecedentes relevantes.

\section{El aumento explosivo de la cobertura educacional}

Así como a mediados del siglo XX América Latina estaba viviendo una inédita bonanza económica, un acelerado proceso de urbanización y un enorme crecimiento demográfico, también estaba siendo escenario de graves tensiones sociales, profundas constricciones económicas y severas fracturas políticas. Tamaño desajuste es el que estaba en la base de dos de los fenómenos más característicos, y dramáticos, que conoció la región en estos años: las dictaduras y las guerrillas. Cabe consignar que una parte importante de la población regional, entre ellos muy especialmente los científicos sociales, se abocará a la tarea de proponer estrategias capaces de profundizar los logros económicos y contener las graves problemáticas sociales, cuestión que en el lenguaje de la época fue comprendido como "desarrollarnos". Se debe agregar, también, que todas las fórmulas ensayadas para propiciar el desarrollo otorgaron un papel importante a la educación, coincidiendo tanto en la comprensión de que era necesario aumentar la cobertura educacional, como en el convencimiento de que había que realizar reformas en el sistema escolar para conseguir este objetivo. Sobre el cómo se fueron concretando estos propósitos, las fuerzas que confluyeron y las dificultades que enfrentaron, es que tratará este artículo.

Pese a que en América Latina la cobertura educacional venía aumentando paulatinamente desde fines del siglo XIX, será solo a mediados del siglo XX que esta tendencia se intensificará 
vertiginosamente, estado en el que se mantendrá hasta la crisis de la deuda externa, es decir, hasta la década de 1980 (Martínez Boom, 2004; Ossenbach, 2001). Donde más claramente es posible dimensionar esta pronunciada expansión educacional es observando el aumento que tuvieron los recursos públicos destinados a la enseñanza y el crecimiento que presentó la matrícula en el nivel primario (Martínez Boom, 2004; UNESCO, 1967). Si por un lado el presupuesto estatal en la materia -el cual constituía las cuatro quintas partes de todos los recursos invertidos en educación- se duplicaba entre los años 1960-1968, por otro lado la matrícula primaria se expandía a una tasa dos veces mayor que la experimentada por el crecimiento demográfico. Datos que se condicen con el hecho de que mientras en 1960 la matrícula del sistema escolar solo abarcaba a poco más del cincuenta por ciento de la población en edad escolar, en 1984 ella se empinaba por sobre los ochenta puntos porcentuales (CEPAL, 1967; Tedesco, 2012).

¿Por qué se produjo este acentuado incremento en la matrícula escolar? ¿Por qué se invirtieron más recursos en la educación? Es que acaso se debía, como sugiere el educador chileno-australiano Robert Austin (2004), a la presión que ejercían los sectores populares a través de sus diferentes formas de lucha. O tal vez respondía, como propone el educador colombiano Alberto Martínez Boom (2004), a una argucia de los sectores dirigentes para poder controlar más fácilmente a los cada vez más numerosos sectores populares.

Sin duda ambas interpretaciones explican una parte del espectacular incremento que tuvo la cobertura educacional, pues así como muchos indicios permiten comprender que el Estado nunca ha concedido beneficios sociales sin luchas de por medio, muchos son también los que nos muestran que la educación sí era uno de los mecanismos de que se valían las elites para cimentar una plataforma cultural funcional a sus intereses. Sin embargo, no se deben desconocer las pistas que permiten comprobar lo contrario, que los sectores populares no necesariamente daban gran importancia a la educación, lo que redunda en que no siempre presionaran para obtenerle, y que el Estado no le promoviera invariablemente como una manera de controlar a los sectores populares, sino como mecanismo para entregar herramientas beneficiosas para el conjunto de la colectividad. Para entender estas aparentes contradicciones y, lo más importante, para comprender las razones que están detrás de la acelerada expansión del sistema educacional, se examinarán minuciosamente los matices existentes en la valoración educacional tanto de los sectores populares como de los sectores dirigentes.

Para introducirnos en las percepciones educacionales de los sectores populares nos apoyaremos en dos apreciaciones proferidas por algunos de los que se investían, en esos años, como portavoces de los sectores populares. Mientras el poeta nicaragüense Ernesto Cardenal (2004) señalaba que un misionero español radicado en su país, Gaspar García Laviana, habría desistido de levantar escuelas para la población rural porque su experiencia le había mostrado que nadie deseaba aprender, el comandante cubano Fidel Castro (1980) sostenía que durante la gesta revolucionaria había constatado, de primera fuente, que los campesinos deseaban alfabetizarse por sobre cualquier otro anhelo.

¿A qué se debían tan dispares opiniones sobre un mismo asunto? ¿Es que acaso uno u otro trataba de desinformarnos? No, ciertamente no. Aunque pueda parecer una obviedad se debe puntualizar que quienes formaban parte de los sectores populares no tenían una valoración 
única de la educación. Esta variaba, y mucho, en función de una infinidad de factores entre los cuales uno, la apreciación que tuvieran respecto de la utilidad de la educación, se asume como cardinal. Si veían que ella no podía servirles en el corto o mediano plazo, como probablemente lo hacían todos los que trabajaban conforme a prácticas tradicionales, entre ellos los campesinos con que trabó contacto Gaspar García Laviana, no solo le ignoraban sino que en algunos casos, inclusive, le despreciaban -ejemplos de ello pueden rastrearse hasta los inicios mismos de la conquista europea- (Donoso Romo, 2012a; Donoso Romo, 2012b; Ponce, 1937). En cambio, si entendían que la educación podía ofrecerles algo de utilidad, aunque sea a largo plazo, como era el caso de los que vieron alteradas sus maneras de trabajar por haber sido desplazados por los hacendados o bien porque se encontraban en medio de un campo de batalla, como los que conoció Fidel Castro, entonces comenzaban a estimarle y, consecuentemente, a demandarle. Eso explica también que tanto en la Cuba como en la Nicaragua revolucionarias una de las primeras medidas implementadas por los insurgentes después de triunfar en la guerra de liberación fuera impulsar sendas campañas de alfabetización, las cuales consiguieron gran resonancia en la población.

Dicho con otras palabras, a medida que en el campo se iba imponiendo el modo de producción industrial, con todos los desdoblamientos económicos, sociales y culturales que ello traía consigo, la población rural iba teniendo más dificultades para mantener sus formas tradicionales de subsistencia, cuestión que hacía que observaran con mejores ojos la posibilidad de migrar a la ciudad. En este escenario la actitud hacia la educación se iba haciendo cada vez más favorable, pues se apreciaba a la escuela, con justa razón, como proveedora de algunos elementos culturales fundamentales para moverse en dicho contexto. Ahí se aprendía la lengua que se hablaba en las urbes, pensaban los indígenas. Ahí se aprendían algunas de las herramientas que permitirían tener un buen pasar en la ciudad, como la lectoescritura y las matemáticas básicas, entendían los campesinos. Ello explica, a su vez, que una vez producida la migración, es decir, ya en la ciudad, prácticamente la totalidad de los sectores populares valoraran positivamente a la educación, demandándole en función de una amplia gama de razonamientos que iban desde el entendimiento de que la escuela era una fuente de alimentación segura para los niños, hasta la apreciación de que ahí se podrían adquirir conocimientos que en el futuro se traducirían en mejores condiciones materiales (Rama, 1987a). Todos argumentos que se encuentran contenidos en una breve reseña sobre la utilidad que tenía la escuela para la población rural que hiciera uno de los principales estudiosos de la educación latinoamericana de estos años, el sociólogo uruguayo Germán Rama:

El hecho de que los niños asistan a la escuela y, principalmente, si pueden terminar los estudios, es una fuente de prestigio dentro de la familia, en la comunidad, y para la familia en la comunidad. La asistencia escolar es una forma de integración al mundo urbano y al país, aunque sea de manera segmentada, limitada y parcial. Por último, los niños siempre aprenden algo, aunque su utilidad inmediata no aparezca con demasiada nitidez. Es poco aplicable en el trabajo predial, sea en el propio predio o en el de otros pequeños productores. Es de mayor aplicación cuando se trata del trabajo en las empresas capitalistas, ya que entonces aparecen otros requerimientos, como firmar recibos o comprobantes, leer los rótulos que indican el contenido de elementos de trabajo, hablar 
la lengua franca, etc. Es más aplicable aún en las actividades de comercialización, ya sea que se realicen por intermediarios o directamente en las ferias locales. Por último, queda la utilidad diferida, pero siempre presente como probabilidad, para la migración temporal o permanente (1987a, p. 243).

Respecto de la valoración que tenían sobre la educación los sectores dirigentes también se dirán algunas palabras, sobre todo porque serán ellos los que a través de su accionar en el Estado viabilizaron la expansión del sistema escolar. Al viejo ideario ilustrado que entendía, por un lado, que la educación de los sectores populares era la llave maestra que les permitiría acceder a los tesoros culturales de la humanidad, y que veía, por otro lado, que ella les proveería herramientas fundamentales para que pudieran ejercer plenamente su soberanía, a mediados del siglo XX los sectores dirigentes latinoamericanos agregan razones de tinte económico que resaltaban que la educación les entregaría conocimientos que permitirían que participaran más eficientemente en el modo de producción imperante. Esta noción, que puede leerse también bajo el prisma de que la educación haría que los trabajadores produjeran más, y con mejor calidad, era la que estaba en la base de la perspectiva que se conoció en estos años, indistintamente, como formación de recursos humanos o como formación de capital humano (Schultz, 1967; Frigotto, 1984; OCDE, 1961).

Aunque al interior de los sectores dirigentes hubo diferentes formas de expresar estas valoraciones, todas ellas coincidían en vincularle protagónicamente a lo que desde entonces se entenderá como desarrollo. Por ello mientras una parte de los sectores dirigentes tendía a comprender que la educación era necesaria para acabar con el atraso e ignorancia que impedían el mentado desarrollo, otra parte entendía que era necesario educar la conciencia de las personas, concientizarnos, para que así efectuáramos las transformaciones estructurales que nos permitirían desarrollarnos. Lo que quiere decir, en último término, que dentro de los sectores dirigentes había quienes discrepaban sobre la importancia que tenía la educación para propiciar el desarrollo, pero así como era difícil encontrar a alguien que cuestionara lo deseable que era desarrollarnos, también era inusitado toparse con alguien que pusiera en duda lo relevante que era la educación.

Todo lo expuesto convida a pensar, como lo insinuara también en estos años el sociólogo argentino Tomás Vasconi (1978), que el aumento de la matrícula educacional estaba íntimamente ligado a la importancia que ella fue adquiriendo para el conjunto de la población, aún cuando todos los actores sociales tendieran a valorar a la educación conforme una articulación particular de juicios y razones. Fenómeno que respondía, a su vez, a las exigencias que nos iban imponiendo la expansión de los modos de producción y de asentamiento imperantes.

\section{Reformando la educación conforme al desarrollo}

Otra de las notas características que tendrá la educación latinoamericana en estos años será la puesta en práctica de ambiciosos planes que tendrán por misión tornar posible estos deseos, y esta necesidad, de ampliar el sistema educacional. Una mirada histórica, 
como la que provee la educadora costarricense Gabriela Ossenbach (2001), permite apreciar que a mediados del siglo XX quienes se preocupaban por las cuestiones públicas evaluaban que el ritmo de crecimiento que hasta entonces llevaba el sistema educacional -el mismo que había comenzado a tomar forma el día después de los triunfos independentistas y que desde las últimas décadas del siglo XIX había adquirido mayor celeridad- no estaba siendo lo suficientemente rápido si se tomaba en cuenta el número potencial de estudiantes. Lo que exigía que se repensaran los sistemas educacionales.

Toda reforma de estos años, independientemente de su magnitud y del color político del gobierno que le impulsara, se propuso alcanzar grandes objetivos del tipo: profundizar la democracia o democratizar la educación. Homogeneidad que respondía, en parte importante, a que la principal institución que promovía estas iniciativas, la recientemente fundada Organización de las Naciones Unidas para la Educación, la Ciencia y la Cultura (UNESCO), se mantuvo invariable. Entre los objetivos educacionales que esta última logró traspasar a todos nuestros países se contaban la necesidad de expandir al máximo la enseñanza primaria, de alfabetizar a toda la población adulta, de asegurar igualdad de oportunidades educacionales y de aumentar las matrículas en la enseñanza secundaria y superior (Coombs, 1978; Martínez Boom, 2004; Tedesco, 2012).

El cómo la UNESCO conseguía influir en las reformas educacionales de estos años se puede explicar por dos vertientes. Primero, porque contaba con equipos de especialistas altamente reconocidos que generaban insumos igualmente prestigiados para que las autoridades gubernamentales tomaran decisiones en la materia. Segundo, porque todos los fondos del exterior que provenían de fuentes oficiales y se destinaban a la educación que fueron muchos en estos años, recuérdese, por ejemplo, lo significativo que fueron en la década de 1960 los capitales movilizados por la Alianza para el Progreso-, debieron contar con su anuencia o, en su defecto, con la de otras instituciones con objetivos afines, como la Organización de Estados Americanos o la Comisión Económica para América Latina y el Caribe (Martínez Boom, 2004; Ossenbach, 2001; Tedesco, 2012).

Si la homogeneidad en materia de reformas se puede entender gracias a los antecedentes dados, la implementación de una reforma tras otra, proceso ininterrumpido hasta la actualidad, no solo se comprende como el resultado de la persistencia de los objetivos inicialmente planteados, es decir, como la necesidad de viabilizar la expansión de la matrícula. También se entiende como consecuencia de la necesaria adecuación que se imponía cuando se instalaba un gobierno con nuevos horizontes, como resultado de los intentos por satisfacer las demandas simultáneas que los diferentes actores le hacían al sistema educacional y/o como expresiones de la búsqueda por encontrar fórmulas que resolvieran los mismos problemas que iban apareciendo con la implementación de las diferentes estrategias. Razones sobre las cuales se agregarán algunas palabras.

Para adentrarnos en la primera justificación apuntada, reformar los sistemas educacionales para ajustarlos a las diferentes estrategias de desarrollo, nos valdremos de un planteamiento que realizara desde la dirección del Instituto Internacional de Planeamiento de la Educación de la UNESCO el estadounidense Philip Coombs (1978). Él sostenía que para contribuir efectivamente al desarrollo la educación debía formar a las personas pensando en su desempeño laboral futuro. Lo que significaba que toda reforma educacional debía 
contemplar el desfase entre el momento que se vivía y la situación deseada e inmediatamente después debía determinar las medidas para alcanzar lo propuesto. Razonamiento que nos autoriza a comprender que cada vez que se reformulaba el plan general de desarrollo nacional, lo que muchas veces coincidía con el cambio de un gobierno a otro, se hacía necesaria una intervención de importantes proporciones en el sistema educacional. Un buen ejemplo de cómo estos fenómenos iban empapando los discursos sobre la educación son las palabras proferidas por el reconocido filósofo peruano Augusto Salazar Bondy, en 1957, a propósito de los desafíos que a su juicio debía enfrentar el país andino en la materia:

Hay que meditar especialmente en los principios y en las directivas a que debe obedecer toda la empresa educativa peruana, así como en las maneras concretas y en los medios prácticos de enseñar en la escuela que el país necesita. Pero al mismo tiempo debemos hacer un balance de los recursos con que contamos actualmente, de sus posibilidades de acrecentamiento y de su más provechosa aplicación, así como una rigurosa selección objetiva de las metas que nos proponemos alcanzar distinguiéndolas según etapas y según radio de aplicación. Es decir, hay que planificar la educación peruana. Sólo haciéndolo podremos cumplir realmente con la obligación de educar de forma cabal a todos los peruanos, y no, como ha ocurrido hasta ahora, sólo a una minoría privilegiada (1965, p. 44).

Sobre la segunda justificación indicada, el reformar los sistemas educacionales para atender apropiadamente las múltiples demandas que los distintos sectores sociales le hacían al sistema escolar, se debe tener presente que ella era una ecuación difícil de resolver en la medida que todos los actores sociales, independientemente de que tuvieran expectativas acordes a sus experiencias, intereses y posibilidades, aspiraban a obtener la mejor educación posible. Por eso, aunque los sectores populares lucharan por acceder al sistema escolar, una gran parte de ellos soñaba con que sus hijos pudieran gozar de estudios universitarios. Ideal que también era el de los cada vez más numerosos sectores medios de la población, los mismos que presionaban por contar con instituciones de educación secundaria de calidad. Y anhelo que también poseían los sectores dirigentes. Aunque claro, se debe precisar que el hecho de que una parte de los sectores dirigentes pudiera concretar dicho anhelo no era impedimento para que demandaran que los niveles primario y secundario pudieran expandir su cobertura para que así aportaran a la conformación de buenos trabajadores, es decir, competentes y disciplinados. Esto último, entre paréntesis, también ayuda a entender el por qué en estos años los sectores dirigentes comienzan a preocuparse por estandarizar los procesos educacionales vía planificaciones y currículos, y es que así, pensaban, se disminuía el riesgo de que los agentes educacionales trabajaran según criterios propios (Coombs, 1978; Rama, 1978a).

Sobre la tercera justificación en que se apoyaban las reformas, la necesidad de idear maneras para subsanar los problemas educacionales derivados, entre otras cosas, de la escasez de recursos, se señala que tal como lo aprecia hoy retrospectivamente el educador argentino Juan Carlos Tedesco (2012), el desafío era hacer más atractivos los servicios educacionales para así mejorar el alto ausentismo, elevar la baja retención de los estudiantes en el sistema y disminuir el elevado número de repitentes. A lo que se debe agregar, también, que aquí se 
encasillaba toda esa presión por alfabetizar a esa población adulta que no estando en edad de participar en el sistema escolar se consideraba prioritario que aprendiera las primeras letras.

Todos estos razonamientos, articulados, fueron los que durante el tercer cuarto del siglo XX dieron vida a dos tipos de reformas: las de carácter estructural, que se proponían contribuir desde el sistema educacional a acabar con las desigualdades económicas, y las de carácter general, que se proponían mejorar la eficiencia interna del mismo sistema. Siendo estas últimas las más frecuentes en razón de que las estructurales, como la que se dio en la Cuba revolucionaria o como la que se proyectó en el Chile de Salvador Allende, debían secundar mudanzas económicas de fondo las cuales, huelga decir, fueron más enunciadas que realizadas (Ossenbach, 2001; Rama, 1987b; Tedesco, 2012).

Independientemente del carácter que asumieran las reformas, todas coincidían en la comprensión de que los elementos del universo escolar que pudieran medirse, cuantificarse y/o controlarse eran los que se debían intervenir. Siendo lo reformable, en último término, todo lo que cupiese adentro de la infraestructura escolar, incluyendo por cierto los contenidos que se enseñaban (Rama, 1987b).

Dentro de las expresiones prácticas que asumieron las reformas uno de sus capítulos más originales fue la decidida promoción de la educación no formal, rótulo que distinguía a todas aquellas instancias que siendo educacionales no formaban parte del sistema escolar. Estas iniciativas se concentraron en la alfabetización de adultos -aunque muchas veces se usaron también para apoyar la implementación de nuevas políticas públicas, como las reformas agrarias, donde se utilizaban para socializar los contenidos técnicos a ellas asociadas- y se implementaron preferentemente en lo rural -aunque muchas escuelas ubicadas en la ciudad comenzaron a realizar turnos nocturnos para poder enseñar las primeras letras a los adultos- (Rama, 1987b).

Entre las características de la educación no formal que más destacan se cuenta el que no se concentraban exclusivamente en asuntos educacionales, pues también se proponían fomentar la participación social, promover liderazgos y/o sensibilizar sobre determinadas problemáticas. Dentro de sus trazos distintivos se cuenta, también, el que prácticamente todas sus experiencias incorporaran estudios previos con los futuros beneficiarios, ello con el objetivo de identificar tanto sus necesidades como sus expectativas en relación a los procesos a emprender.

Pese a que la educación no formal cobró mucha relevancia a mediados del siglo XX, fue en la década de 1980 que conoció sus mejores años. Fue aquí, cuando las deudas de nuestros países empujaban a las elites gobernantes a recortar los gastos sociales del Estado, que muchas organizaciones de cooperación internacional de los países ricos comienzan a financiar copiosamente iniciativas de esta naturaleza. Movimiento que tuvo tal magnitud que las organizaciones no gubernamentales que les implementaban llegaron a transformarse en una especie de para-Estado, fenómeno que todavía hoy es común observar en nuestros países más pobres (Gentili, 2012).

La sola presencia de estas iniciativas de educación no formal muestra que la tarea de ampliar la cobertura a los niveles deseados no fue una cuestión simple. Era difícil encontrar una formulación consistente de desarrollo, así como complicado era ajustar el sistema escolar a dicha comprensión y complejo era satisfacer, simultáneamente, los intereses que cada uno de los sectores sociales ponía en el ruedo. Siendo estas dificultades, y sobre todo los cuestionamientos que se hicieron a las estrategias implementadas para sobrellevarles, las que se aprecian en el siguiente apartado. 


\section{El otro lado de la cima: críticas al sistema escolar}

Los mejores años de la educación en América Latina, aquellos en que su importancia para una parte importante de la población fue prácticamente indiscutida, en que se amplió exponencialmente la matrícula escolar y en que se sucedieron las reformas tendientes a permitir dicho crecimiento, también fueron momentos controversiales en que varios especialistas, y una parte significativa de los sectores medios, comenzaron a cuestionar muchos atributos del sistema escolar. Entre las principales críticas que se levantaron sobresalen tres: que la ampliación de la matrícula no estaba favoreciendo a todos los sectores sociales, que se estaba beneficiando con más recursos públicos a los que comparativamente menos les necesitaban y que la educación escolar se iba tornando un emprendimiento cada vez más pesado, económicamente hablando, para los estados. Tres cuestionamientos sobre los cuales se añadirán algunas precisiones.

Respecto de la primera crítica enunciada se apunta que, ya en esos años, se tendía a observar que la expansión de la matrícula seguía un patrón concéntrico, es decir, comenzaba en los centros de poder de nuestras sociedades para luego ir extendiéndose, en la medida de lo posible, a las áreas marginales. Lo que significa que primero se beneficiaba a las capitales, después a las grandes ciudades, luego a sus áreas adyacentes y, al final, a los sectores rurales. Por ello, aunque efectivamente la demanda educacional fuese más sentida en las aglomeraciones urbanas y pese a que la instalación de instituciones educacionales fuese más rentable en los asentamientos más densamente poblados, no serán pocos los que cuestionarán esta lógica, sobre todo porque ella no resguardaba de la misma manera las posibilidades educacionales de toda la población en edad escolar (CEPAL, 1967; Tedesco, 2012).

La segunda crítica decía relación con que la provisión educacional era selectiva, pues pese a que los estados se proponían otorgar servicios educacionales equivalentes a toda la población, en la práctica estaban entregando más y mejores prestaciones a los que más recursos tenían, los sectores medios y dirigentes. Eso explica que las escuelas públicas contaran, por lo general, con instalaciones más precarias cuando atendían a los niños de los sectores populares. También torna inteligible, al menos en parte, el hecho de que el analfabetismo sea hasta hoy mucho más alto en los campos que en las ciudades y más elevado aún entre aquellas poblaciones con menos vínculos con los sectores dirigentes, como los indígenas (Rama, 1987a). Además ayuda a elucidar el hecho de que las matrículas de las escuelas primarias fueran las que cuantitativamente más crecieran, pero no las que más aumentaran en términos proporcionales. Sí, porque fue la matrícula de las instituciones secundarias y universitarias, aquellas que servían específicamente a los sectores medios y dirigentes, la que crecerá más acentuadamente, tal como lo evidencian estos datos referidos a la década de 1960 en América Latina y que muestran que mientras la matrícula de la educación primaria se incrementaba en un $65 \%$, la secundaria lo hacía en un $178 \%$ y la superior en un 182\% (CEPAL, 1967; Martínez Boom, 2004; UNESCO, 1967). Aumento que, es necesario precisar, no solo era resultado de la alta valoración de la educación que tenían estos sectores sociales, también respondía a los procesos económicos y sociales en curso pues estos pedían cada vez más personal calificado para las cada vez más numerosas industrias, empresas e instituciones tanto públicas como privadas. 
Para que no quede ninguna duda sobre el cuestionamiento referido, se añade que en algunas de nuestras sociedades los recursos que se invertían en los estudiantes de los sectores medios y dirigentes llegaban a ser montos hasta treinta veces más altos que los que se destinaban a la educación de los estudiantes provenientes de los sectores populares (Rama, 1987a). Diferencia que no solo se explica porque los estudiantes más pobres tendían a abandonar más tempranamente el sistema, sino porque los servicios ofrecidos a estos últimos eran de menor calidad. Lo que quiere decir que la inversión pública en los estudiantes de los sectores populares era menor y, por un tiempo más breve, que la que disfrutaban los estudiantes de los otros sectores.

La tercera crítica que comienza a aflorar en estos años es la que refiere a que la educación se estaba tornando inviable económicamente. Ello en razón de que año tras año los estados debían aumentar los recursos destinados a la educación para obtener los mismos estándares de cobertura/calidad. Dinámica que obedecía a que el número de personas que integraban al sistema iba en constante ascenso y, a su vez, a que cada vez más estudiantes avanzaban a los grados superiores. Todo lo cual redundó en que cundiera la apreciación de que no estaba lejos el día en que se desfinanciaría el sistema (Coombs, 1978; Illich, 1973; Reimer, 1976).

Luego de esbozado el espíritu de las principales críticas que en estos años se levantan en contra del sistema escolar se debe consignar que no solamente los especialistas estuvieron preocupados por los asuntos educacionales. Ya en los albores del siglo XX algunos intelectuales, pertenecientes a los emergentes sectores medios de la población, manifestaron inquietudes similares que terminaron traduciéndose en experiencias educacionales al margen del sistema escolar, como por ejemplo las así llamadas universidades populares (Donoso Romo, 2012b). A mediados del siglo estas perspectivas críticas cobraron renovadas energías de la mano de gobiernos afines a los sectores populares, como los liderados por João Goulart en Brasil o Eduardo Frei Montalva en Chile. En ambas experiencias los estados comienzan a innovar con miras a dotar a los sectores populares de servicios educacionales que no significaran necesariamente un aumento en los costos. Siendo aquí cuando empiezan a proliferar las experiencias de educación no formal, las mismas que se entenderán como "educación popular" cuando se multipliquen los gobiernos autoritarios de signo conservador y la oposición se apropie de estas experiencias valorándolas como prácticas de resistencia (Almada, 1989; Almada, 2005).

Esta familiaridad entre educación no formal y educación popular, como bien advierte la educadora argentina Adriana Puiggrós (1994), hace que muchas veces les confundamos. Y es que efectivamente compartieron, y comparten, muchas aristas tanto en sus diagnósticos como en sus propuestas. No obstante, se debe hacer notar que ellas poseen una diferencia fundamental, mientras las experiencias de educación no formal se fundan en la necesidad de ampliar la cobertura educacional por vías alternativas al sistema escolar, las iniciativas de educación popular se proponen ser funcionales a los sectores populares. Lo mismo pero con otras palabras, si la educación popular estaba, en primer lugar, al servicio de los sectores populares, la educación no formal respondía primero a las directrices estatales. Siendo apropiado recordar que hubo momentos en donde los estados, por estar controlados por actores afines a los sectores populares, impulsaron iniciativas de educación no formal que podían entenderse también como educación popular. 
Profundizando en lo que fueron las experiencias de educación popular, se apunta que ellas efectivamente se fueron erigiendo con el objetivo de subsanar algunos vacios en la cobertura del sistema escolar, también como respuesta a la menor calidad de las iniciativas educacionales destinadas a los sectores populares y/o para contrarrestar los impedimentos que no dejaban que estos últimos progresaran en el sistema escolar. Sobre estos impedimentos se apunta que los hijos de los sectores populares que conseguían resistir a la tentación de desertar de la escuela y accedían a la enseñanza secundaria -lo que significaba que no la abandonaban a causa de la precaria educación recibida ni por la necesidad de trabajar en pro del sustento familiar-, rápidamente percibían que la base que habían adquirido no era de la misma factura que la que habían recibido quienes provenían de los otros sectores sociales y que, por lo mismo, solo un esfuerzo extraordinario podría permitirles acompañar las clases (CEPAL 1967; CEPAL, 1982). Siendo esto mismo lo que el educador argentino Pablo Gentili (2008) refuerza hoy cuando señala que se debe evaluar con mesura el aumento en la cobertura educacional porque si antes los sectores populares se veían impedidos de entrar al sistema, ahora podían hacerlo pero a una versión deslucida del mismo. En sus palabras:

A lo largo de la historia, y con poquísimas excepciones (como el caso cubano después de los años 60), los países de América Latina y el Caribe desenvolvieron sus sistemas educacionales en medio de un proceso de profunda segmentación, creando redes institucionales diferenciadas, tanto desde el punto de vista de las condiciones materiales otorgadas en cada segmento como de las oportunidades educacionales por él ofrecidas. Esta segmentación cuestiona la propia noción de "sistema nacional de educación" en buena parte de los países de la región. En rigor, en la medida en que tendían a democratizar las oportunidades de acceso, los sistemas escolares se tornaron mas segmentados, definiendo una serie de "circuitos" tan dispares entre sí que hacen imposible comparar las experiencias educacionales efectivamente vividas por aquellos que en ellos permanecen. Es evidente que, en América Latina, las oportunidades de acceso al "otro circuito" se definen no por el talento de los estudiantes, ni por la libre elección de los padres, sino por las condiciones de vida, por los recursos materiales de que disponen las familias y por las muchas y eficaces formas de segregación reproducidas socialmente. $\mathrm{O}$ sea, por la clase, por la condición sexual, étnica o racial (p. 35) ${ }^{2}$

Para completar esta panorámica de las críticas que comienzan a levantarse en el plano educacional se recuerda que serán los universitarios uno de los actores que más duramente enjuiciarán al sistema escolar. Ellos reverdecerán cuestionamientos que hacía varias décadas habían esparcido por todo el continente los estudiantes de Córdoba y, como ellos, denunciarán que la universidad estaba dándole la espalda a las dificultades de todo orden que afectaban a nuestros países, aislándose. "El movimiento de reforma universitaria" como se le llamó a mediados del siglo XX en Bogotá, Santiago de Chile y otras ciudades de la región, se hizo tangible en experiencias de trabajo voluntario, muchas de ellas entendidas como educación popular, y en manifestaciones públicas de descontento, ya sea frente a las problemáticas educacionales similares a las descritas o bien frente a los abusos que cometían los gobiernos autoritarios.

Traducción libre hecha por el autor. 
Mientras desde adentro estos estudiantes se veían a sí mismos como agentes de transformación social, en el espíritu de lo cantado por el brasileño Geraldo Vandré en Para que no digan que no hablé de las flores. Desde afuera muchos analistas han tendido a apreciarles, a posteriori, como una parte de los sectores medios que por sentir que no tenían cabida en la sociedad de su tiempo se revelaban para hacerse un espacio en ella (Rama, 1987b; Ridenti 2010).

Independientemente de los motivos que impulsaban a los universitarios a irrumpir con una voz disidente, cabe destacar que la masividad de algunas de sus iniciativas se veía facilitada porque se encontraban inmersos en espacios cerrados que contribuían a una rápida socialización de sus demandas y también porque sus centros de estudios se encontraban en grandes ciudades, lo que favorecía que multiplicaran su impacto gracias a la amplia cobertura que les daba la prensa (Hobsbawm, 2003). No obstante, nada de esto les libró de la dura represión que sobre ellos desataron los gobiernos que les veían como agitadores, rebeldes y/o desestabilizadores. De eso pueden dar fe los miles de universitarios brasileños que en estos años terminaron en las cárceles y los miles de estudiantes mexicanos que vieron como cientos de los suyos fueron asesinados por uniformados en la víspera de los juegos olímpicos de 1968 (Poerner, 1995; Poniatowska, 2010).

Toda esta fuerza represiva terminó siendo eficaz en su propósito de hacer retroceder a los movimientos estudiantiles, momento que coincidirá, además, con la baja sostenida que comenzarán a sufrir los presupuestos públicos destinados a la educación. La educación dejaba de ser así, en los hechos, prioritaria para las elites y sus estrategias de desarrollo. Cuestión que no se entiende, únicamente, como una consecuencia de que los sectores dirigentes hubieran dejado de creer en las bondades de esa educación que tantos dolores de cabeza les habría causado -sobre todo por estos universitarios rebeldes y por estos jóvenes profesionales que alentaban la educación popular-, se debía también a que un acontecimiento económico extraregional, como tantas otras veces nos había ocurrido, ponía en jaque a nuestras economías.

\section{Conclusión}

Desde mediados de los años setenta todos los países de la región se verán obligados a desestimar su estrategia de crecimiento económico basada en la industrialización inducida por el Estado, que era la misma que pedía un aumento constante en los niveles educacionales de la población, debido a que el explosivo aumento en los precios del petróleo hicieron que nuestros países se sobre-endeudaran. Cuando ya no se pudo seguir obteniendo préstamos para pagar antiguos créditos, es decir, cuando nos tornamos financieramente insolventes, aquella parte de los sectores dirigentes que controlaban los estados se vio compelida a obtener de alguna parte los recursos para pagar lo adeudado, optando por sacrificar los gastos en política social y, entre los primeros, los educacionales. Así comenzaba a imponerse decididamente el neoliberalismo, doctrina que privilegiará el libre accionar de los agentes económicos en el Mercado y que restringirá al máximo la injerencia del Estado en todos los ámbitos, también el educacional (Abel, 2008). Desde ahora en adelante las preguntas que orientarán las políticas públicas en la materia no serán, como antaño, aquellas relativas a cómo poder aumentar más la cobertura educacional, sino a cuanto es lo mínimo que el Estado debía invertir para tener un sistema educacional razonable o, en los casos más extremos, como lo esclarece el educador 
chileno Sebastián Donoso, cuanto es lo mínimo que el Estado debía invertir para asegurar el máximo de beneficios a los empresarios educacionales (Donoso Díaz, 2013).

De esta manera fueron quedando atrás muchas décadas donde imperaba el optimismo pedagógico, aquella comprensión compartida por gran parte de la población latinoamericana y que veía que la educación era la solución casi para cualquier mal. Para dar paso al pesimismo educacional, sensibilidad en donde el sistema escolar pierde centralidad en la lucha por el desarrollo (Martínez Boom, 2004). Tránsito que se producirá, entre otras cosas, porque cada vez serán más las personas que comenzarán a ver a la educación como un sistema perverso que solo permitía la reproducción de todo lo necesario para que las elites se mantuvieran en dicha condición -interpretaciones en línea con las popularizadas por los intelectuales franceses Louis Althusser (1985), Pierre Bourdieu y Jean Claude Passeron (1982)-. Tránsito que se deberá, también, a que muchos de los defensores de las ideas neoliberales empezarán a esparcir la comprensión de que la educación era irrelevante para la obtención de mejores resultados en lo que a crecimiento económico se refiere, valoración que será más evidente en los hechos que en los discursos (Gentili, 2008; Rama, 1987b).

Los mejores años de la educación en América Latina, aquellos en donde la educación estuvo en el centro de incontables debates y programas, llegaban así a su fin. Todavía hoy los fenómenos inaugurados en estos años siguen desenvolviéndose, aunque no con el protagonismo y la fuerza que entonces evidenciaran. La cobertura educacional continua aumentando, las reformas se siguen sucediendo y las críticas a estos procesos siguen alimentando nuevas experiencias de educación no formal y/o educación popular. Lo que nos toca a nosotros, en tanto, es ir afinando la comprensión en torno a las causas y razones que dan sentido a estos procesos educacionales, pues un entendimiento más aguzado no solamente permitirá idear mejores propuestas, lo más importante es que tengamos mejores prácticas. A ese objetivo esperamos haber contribuido.

\section{Referencias}

Abel, C. (2008). La política social en América Latina desde 1930 hasta el presente. En Palacios, Marcos y Weinberg, Gregorio. Historia general de América Latina, tomo VIII. América Latina desde 1930 (pp. 213-251). París: UNESCO - Editorial Trotta.

Almada, M. (1989). Paraguay: educación y dependencia. (2 Ed.). Asunción, Paraguay: Intercontinental Editora. DOI: http://dx.doi.org/10.2307/3282780

Almada, M. (2005). Paraguay: la cárcel olvidada con anexo documental novena edición. $\left(9^{\circ}\right.$ Ed.) La Habana: Encuentro Internacional Contra el Terrorismo, Verdad y Justicia. Recuperado de http://es.calameo.com/read/000028645fee8325fefec

Althusser, L. (1985) [1970]. Aparelhos ideológicos de Estado. Rio de Janeiro: Edições Graal.

Austin, R. (2004). Intelectuales y educación superior en Chile, de la independencia a la democracia transicional 1810-2001. Santiago de Chile: Ediciones Chile América - CESOC. 
Bourdieu, P. y Passeron, J. C. (1982) [1970]. A reprodução. Rio de Janeiro: Francisco Alves Editora.

Cardenal, E. (2004). La revolución perdida. Memorias 3. Madrid: Editorial Trotta.

Castro, F. (1980) [1976]. La educación en la revolución. México D.F.: Ediciones de Cultura Popular.

CEPAL (1967). Educación, recursos humanos y desarrollo en América Latina. Nueva York: Naciones Unidas.

CEPAL (1982). El desarrollo de América Latina y sus repercusiones en la educación. Alfabetismo y escolaridad básica. Santiago de Chile: CEPAL.

Coombs, P. (1978) [1968]. La crisis mundial de la educación. Barcelona: Edicions 62.

Donoso Romo, A. (2012a) [2008]. Educación y nación al sur de la frontera: organizaciones mapuche en el umbral de nuestra contemporaneidad, 1880-1930. Santiago de Chile: Editorial Pehuén.

Donoso Romo, A. (2012b). Identidad y educación en América Latina. Ensayos. Caracas: Editorial Laboratorio Educativo.

Donoso Díaz, S. (2013). El derecho a educación en Chile: Nueva ciudadanía tras el ocaso neoliberal. Santiago de Chile: Bravo y Allende Editores.

Frigotto, G. (1984). A produtividade da escola improdutiva. São Paulo: Cortez Editora.

Gentili, P. (2008). Desencanto e utopia: a educação no labirinto dos novos tempos. Petrópolis: Editora Vozes.

Gentili, P. (2012) [2011]. Pedagogía de la igualdad. Ensayos contra la educación excluyente. Buenos Aires, Siglo XXI.

Hobsbawm, E. (2003) [1994]. Era dos extremos. O breve século XX. 1914-1991. São Paulo: Companhia das Letras.

Illich, I. (1973). En América Latina ¿Para qué sirve la escuela? Buenos Aires: Ediciones Búsqueda. 
Martínez Boom, A. (2004). De la escuela expansiva a la escuela competitiva: Dos modos de modernización en América Latina. Barcelona: Anthropos.

OCDE (1961). El desarrollo económico y las inversiones en educación. Washington: Organización de Cooperación y Desarrollo Económicos.

Ossenbach, G. (2001). Génesis histórica de los sistemas educativos. En García, J. Ossenbach, G. y Valle, J. Cuadernos educación comparada 3, Génesis, estructuras y tendencias de los sistemas educativos iberoamericanos (pp. 13-60). Madrid: Organización de Estados Iberoamericanos.

Poerner, A. J. (1995). O poder joven. História da participação política dos estudantes brasileiros. São Paulo: Centro de Memória da Juventude.

Ponce, A. (1937). Educación y lucha de clases. México D.F.: Editorial América.

Poniatowska, E. (2010). Tlatelolco para universitarios. Em Varios autores. ¡No se olvida! Testimonios del 68 (pp. 9-17). México D.F.: Para leer en libertad y PRD - DF.

Puiggrós, A. (1994). Historia y prospectiva de la educación popular latinoamericana. En Gadotti, M. y Torres, C. (orgs.) Educação popular: utopia latino-americana (pp. 13-22). São Paulo: Cortez / Editora da Universidade de São Paulo.

Rama, G. (Coord.) (1987a). Desarrollo y educación en América Latina y el Caribe, tomo 1. Buenos Aires: CEPAL/UNESCO/PNUD/Kapelusz.

Rama, G. (Coord.) (1987b). Desarrollo y educación en América Latina y el Caribe, Tomo 2. Buenos Aires: CEPAL/UNESCO/PNUD/Kapelusz.

Reimer, E. (1976) [1970]. La escuela ha muerto: alternativas en materia de educación. Buenos Aires: Barral Editores.

Ridenti, M. (2010). Artistas e intelectuales brasileños en la décadas de 1960 y 1970: cultura y revolución. En Altamirano, C. (dir.) Historia de los intelectuales en América Latina (pp. 372-394). Madrid: Katz.

Salazar Bondy, A. (1965). En torno a la educación. Ensayos y discursos. Lima: Facultad de Educación Universidad Nacional Mayor de San Marcos. 
Schultz, T. (1976) [1963]. O valor econômico da educação. Rio de Janeiro: Zahar Editores.

Tedesco, J.C. (2012). Educación y justicia social en América Latina. Buenos Aires: Fondo de Cultura Económica.

UNESCO (1967). Educación y desarrollo en América Latina: bases para una política educativa. Buenos Aires: UNESCO/ Editorial Solar.

Vasconi, T. (1978) [1973]. Contra la escuela, Bogotá: Librería y Editorial América Latina. 